\title{
АРТЕРИАЛЬНАЯ ГИПЕРТЕНЗИЯ В ДИАГНОСТИКЕ МЕТАБОЛИЧЕСКОГО СИНДРОМА
}

\section{Блинов А.В., Макрушин И.М., Гришкин А.Н.}

ГБУЗ «ДГП №42 ДЗМ»

Цель исследования: установить частоту встречаемости артериальной гипертензии (АГ) у детей и подростков в составе метаболического синдрома.

Объект исследования и методы: проведено комплексное обследование 161 пациента с

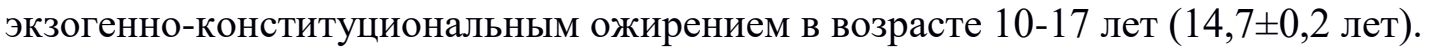

Всем пациентам проводилось суточное мониторирование артериального давления (СМАД) осцилометрическим методом на аппарате фирмы «Bplab», электрокардиография в 12 отведениях на электрокардиографе «Поли-Спектр - 8/Е» фирмы Нейрософт и эхокардиография, на аппарате Vivid $\mathrm{S} 70 \mathrm{~N}$ в сочетании с допплерографическим исследованием. Метаболический синдром (МC) выставлен согласно педиатрическим критериям Международной федерации диабета (IDF, 2007; P. Zimmet, 2007).

Все обследуемые были разделены на две группы: пациенты у которых был диагностирован МС $(\mathrm{n}=58)$ и пациенты без МС (n=103).

Результаты: частота МС среди детей и подростков с ожирением составила $36 \%$. Наиболее частый клинический вариант МС это трехкомпонентная форма - 75,9\% включающая наряду с абдоминальным ожирением АГ и сниженный уровень ЛПВП.

По результатам обследования АГ была диагностирована у 86 пациентов, что составило 53,4\% среди всех обследованных из них стабильная - 59 (68,6\%) пациентов и лабильная - $27(31,4 \%)$ пациентов $(\mathrm{p}<0,001)$. У пациентов с МС АГ выявлена у 49 пациентов $(84,5 \%)$ в группе пациентов без MC АГ у 37 пациентов (35,9\%) (p<0,001). В группе пациентов с МС стабильная АГ $35(71,4 \%)$ диагностировалась достоверно чаще чем лабильная $14(28,6 \%)(\mathrm{p}<0,01)$.

Кроме того, выявлены статистически значимые различия между группой пациентов с МС и без него в уровне мочевой кислоты 436,1 $\pm 10,0$ и $375,3 \pm 8,3$ (р<0,001) и показателя индекса времени

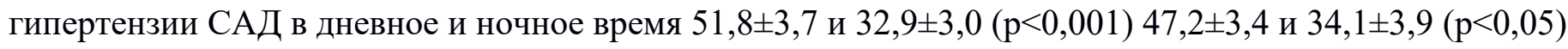
соответственно. Уровень систолического артериального давления (АД) при офисном измерении при МC был также значимо выше $130,4 \pm 1,7$ и $123,6 \pm 1,4(\mathrm{p}<0,01)$, уровень диастолического АД между

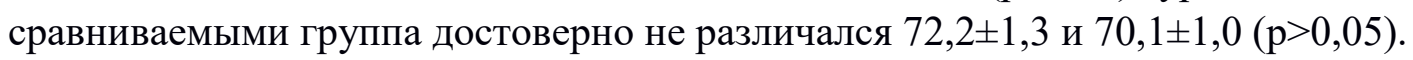

По результатам анализа электрокардиограмм и ЭХО-КГ не получено патологических изменений, а также достоверных различий между сравниваемыми группами.

Выводы: среди пациентов с ожирение каждый второй имеет признаки артериальной гипертензии - 53,4\%, у каждого третьего был диагностирован МС - 36\% среди которых АГ выявляется в $84,5 \%$ случаев. Причем у пациентов с МС в $89,8 \%$ случаев уровень систолического артериального давления был достоверно выше уже при офисном измерении, СМАД лишь только подтвердил данные изменения. Использование СМАД помимо оценки особенностей суточного профиля АД позволило избежать гипердиагностики за счет исключения феномена «белого халата».

Так же при оценке АГ при МС подтвердилась давно известная связь между уровнем АГ и мочевой кислоты, отмечаемая многими исследователями. Таким образом гиперурикемию можно использовать как критерий для формирования группы риска по АГ в амбулаторных условиях. 